- Trabalho apresentado no $\checkmark$ Congresso Brasileiro de Parasitologia, Rio de Janeiro, 26 a 29 de fevereiro de 1980.
** Superintendência de Controle de Endemias - SUCEN - da Secretaria de Estado da Saúde de São Paulo.

**"Instituto de Ciéncias Biomédicas da Universidade de São Paulo.

Recebido para publicação em $23 / 04 / 85$

\section{Soroepidemiologia da infecção chagásica: contribuição para o aumento do rendimento da reação de imunofluorescência indireta *}

\author{
Maria Esther de Carvalho** \\ Cláudio Santos Ferreira ***
}

O trabalho de sorodiagnóstico realizado no Laboratório de Imunofluorescência da SUCEN é parte de um sistema de coleta de dados epidemiológicos sobre a doença de Chagas em todo o Estado de São Paulo. A demanda de trabalho, ponto básico para o dimensionamento de recursos a serem postos à disposição do setor, gera, obviamente, uma pressão no sentido do aumento da eficiência. Como resposta, mantemos, paralelamente ao trabalho corrente de realização de exames de amostras de sangue e de soro, além do controle de qualidade exigivel, constante atividade de pesquisa visando ao refinamento das técnicas em uso. Sempre que o justifiquem os resultados dessa pesquisa, novas técnicas passam a fazer parte da atividade quotidiana ${ }^{3}$.

Em considerável parcela do nosso Estado é, atualmente, baixa a prevalência da infecção chagásica, sendo grandes as percentagens de resultados negativos de exames sorológi$\cos ^{1,2,4,5}$.

Inquéritos soroepidemiológicos realizados em populações em que é baixa a percentagem de casos positivos tornar-se-ão menos laboriosos se conjuntos de soros, previamente misturados, forem manipulados como um só caso, repetindo-se individualmente as reaçбes de todos os integrantes dos conjuntos em que os resultados foram positivos 6 .

Admitindo-se a mistura de amostras escolhidas aleatoriamente, a probabilidade $\mathrm{P}$ de um conjunto de $\mathrm{n}$ casos conter pelo menos um positivo é dada pela fórmula (1):

$$
\mathrm{P}=1-(1 \cdot \mathrm{p})^{\mathrm{n}}
$$

em que $\mathrm{p}$ é a freqüência de casos positivos na população ${ }^{6}$.

A técnica de coleta de amostras de sangue em papel-filtro tem limitado, como demonstraram experimentos prévios, o número de amostras a serem processadas simultaneamente a apenas duas, mantida a diluição de 1:40 (ou de 1:32) recomendada para casos de amostras de um só caso. 
No experimento descrito, os resultados finais de exames de 6.578 casos concordaram inteiramente com os das duplicatas processadas individualmente.

O número de exames economizados, observado na Tabela 1 , pode ser estimado aplicando-se a fórmula (2):

$$
R_{1}=(0,5-P) 100
$$

em que $R_{1}$ é o rendimento de reações qualitativas expresso em percentagem.

\section{TABELA 1}

Rendimento das reações qualitativas no processamento simultâneo de pares de amostras

\begin{tabular}{ccr}
\hline $\begin{array}{c}\text { Frequiência relativa de } \\
\text { positividade na } \\
\text { população }(\mathrm{p})\end{array}$ & $\begin{array}{c}\text { Probabilidade, em cada 2 } \\
\text { amostras, de pelo menos } \\
\text { 1 ser positiva (P) }\end{array}$ & $\begin{array}{c}\text { \% de exames } \\
\text { economizados }\end{array}$ \\
\hline 0,00 & 0,0000 & 50,00 \\
0,01 & 0,0199 & 48,01 \\
0,02 & 0,0396 & 46,04 \\
0,03 & 0,0591 & 44,09 \\
0,04 & 0,0784 & 42,16 \\
0,05 & 0,0975 & 40,25 \\
0,10 & 0,1900 & 31,00 \\
0,15 & 0,2775 & 22,25 \\
0,20 & 0,3600 & 14,00 \\
0,25 & 0,4375 & 6,25 \\
0,30 & 0,5100 & $-1,00$ \\
\hline
\end{tabular}

Embora teoricamente, para $n=2$, uma freqüência de positividade da ordem de $28 \%$ ainda permita economizar reações (Tabela 1), considerações de ordem prática nos levaram a estabelecer o limite de $24 \%$ de casos positivos na população como o mais conveniente.

Nas oportunidades em que se devam titular os casos positivos observados na triagem, pode ser vantajoso o processamento de conjuntos de soros, dependendo do número de diluições os limites de percentagem de positividade aceitáveis. $\mathrm{Na}$ Tabela 2, é ilustrado, apenas como exemplo, o caso em que são utilizadas quatro diluições a partir da triagem 1:32. Os dados de que se compõe resultam da aplicação da fórmula (3):

$$
R_{2}=\left(1-\frac{0,5+k P}{1+k p}\right) 100
$$

em que $R_{2}$ é o rendimento de reações quantitativas expresso em percentagem e $\mathrm{k}$ o número de diluições de soro utilizadas.

Caderno de Saúde Pública, R.J., 1(4): 478-481, out/dez, 1985. 
TABELA 2

Rendimento das reaçôes quantitativas no processamento simultâneo de pares de amostras

\begin{tabular}{ccc}
\hline $\begin{array}{c}\text { Freqüência relativa de } \\
\text { positividade na } \\
\text { população (p) }\end{array}$ & $\begin{array}{c}\text { Probabilidade, em cada 2 } \\
\text { amostras, de pelo menos } \\
1 \text { ser positiva (P) }\end{array}$ & $\begin{array}{c}\text { \% de exames } \\
\text { economizados }\end{array}$ \\
\hline 0,01 & 0,0199 & 44,27 \\
0,02 & 0,0396 & 39,04 \\
0,03 & 0,0591 & 34,25 \\
0,04 & 0,0784 & 29,86 \\
0,05 & 0,0975 & 25,83 \\
0,06 & 0,1164 & 22,13 \\
0,07 & 0,1351 & 18,72 \\
0,08 & 0,1536 & 15,58 \\
0,09 & 0,1719 & 12,68 \\
0,10 & 0,1900 & 10,00 \\
0,12 & 0,2256 & 5,24 \\
0,14 & 0,2604 & 1,18 \\
0,16 & 0,2944 & $-2,29$ \\
\hline
\end{tabular}

Permanecendo em curso o experimento, novos dados serão acrescentados para conhecimento pormenorizado das vantagens, já evidentes, de conduta que visa à redução de custos operacionais e aumento de eficiência de trabalhos aplicados a inquéritos epidemiológicos endereçados a gran. des setores da população.

\section{REFERÊNCIAS BIBLIOGRÁFICAS}

1. CARVALHO, M.E. de; DIAS JR., J; FERREIRA, C.S. \& FRANCISCO S.M. Infecção chagásica em localidades do município de Taquarituba (SP): dados soroepidemiológicos. In: CONGRESSO BRASILEIRO DE HIGIENE, 19ㅇ São Paulo, 10 14 ou t. 1977. Resumos. São Paulo, 1977. 10.4.

2. CARVALHO, M.E. de; FRANCISCO, S.M. \& LITVOC, J. Níveis de anticorpos anti-Trypanosoma cruzi em população ru ral de alguns municípios do Estado de São Paulo. In. CONGRESSO DA SOCIEDADE BRASILEIRA DE MEDICINA TROPICAL, 15 Campinas, SP, 4-8 fev. 1979 Resumos. São Paulo, 1979.

3. FERREIRA, C.S. \& CARVALHO, M.E. de. Reações de imunoflu orescência indireta: algumas modificações de sua técnica. R. Saúde públ., São Paulo, 7: 303-6, 1973.

4. GUARITA, O.F.; DIAS JR. J.; CARVALHO, M.E. de; VALÉRIO, D.M.B. \& SALVO, A. de. Infecção chagásica: inquérito escolar em alguns municípios do Estado de São Paulo, por meio de reação de imunofluorescência indireta, de 1973 a 1978. In: CONGRESSO DA SOCIEDADE BRASILEIRA DE MEDICINA TROPICAL, 159 Campinas, SP, 4-8 fev. 1979. Resumos. São Paulo, 1979.

Caderno de Saúde Pŕblica, R.J., 1(4):478-481, out/dez, 1985. 
5. MELlO, C. da S.; SALVO, A. de; ROCHA E SIlVA, E.O. da; DIAS JR. J.; NODA, J.; CARVALHO, M.E. de \& GUARITA, O.F. Estudo epidemiológico relativo à infeçãa chagásica no município de Taquarituba, SP, realizado no período de 1974 a 1976. In: CONGRESSO BRASILEIRO DE HIGIENE, 15? São Paulo, 10-14 out. 1977. Resumos. São Paulo, 1977, 10.5

6. SACHS, L. Statistische Auswertungsmethoden. 2 ed. Berlin, Springer Verlag, 1969. 